\title{
Analysis of an Underground Water-Sealed Oil Storage Cavern: a Method of Surrounding Rock Classification Considering Hydrological Conditions
}

\author{
Yiguo Xue*, Yufan Tao, Daohong Qiu, Maoxin Su, Zhiqiang Li, Xueliang Zhang \\ ${ }^{1}$ Geotechnical and Structural Engineering Research Center, Shandong University, Jinan 250061, Shandong, China
}

Received: 1 July 2020

Accepted: 5 September 2020

\begin{abstract}
Changes in hydrogeological conditions directly affect the utility of water curtain systems and the safety of oil storage caverns during the construction and operation of underground water-sealed oil storage caverns. Therefore, hydrogeological conditions are of great importance in surrounding rock classification. This study is based on an actual project. The PCA-extenics model is applied to evaluate the exact hydrogeologic grade of the oil storage cavern. Then, the authors introduce rough set theory to calculate the weight of each influential factor. Finally, the research establishes the RS-extenics model for surrounding rock prediction based on the weights and evaluates the reliability of the model. The results suggest that the $R Q D$ has the most significant weight (0.3158) and is crucial to surrounding rock classification. The prediction results are generally consistent with the actual values. The results indicate that the model has good engineering applicability and value. The study provides a reference for the prediction of hydrogeological grades and classification of rock surrounding oil storage caverns.
\end{abstract}

Keywords: underground water-sealed oil storage cavern, extenics, rough set theory, hydrogeological classification, surrounding rock classification

\section{Introduction}

Establishing strategic petroleum reserves is an effective way of addressing shortages in the short-term oil supply. The features of underground water-sealed oil storage caverns include long spans, high sidewalls, no linings and no or few support measures. During

*e-mail: xieagle@sdu.edu.cn

the construction of an actual project, the underground water level in some areas can sharply drop, which directly threatens the utility of the water system and the safety of the oil storage cavern. Therefore, it is essential to evaluate the hydrogeological conditions of oil storage caverns properly. The relevant construction methods must be modified based on new surrounding rock classification schemes.

Many studies about the analysis, design and the construction of underground storage caverns have been conducted [1-7]. Many scholars have also investigated 
the stability and sensitivity of the rock surrounding underground caverns [8-12].

Many scholars have conducted studies to evaluate and classify the surrounding rock in underground engineering projects [13-16]. However, with developments in science and technology, single-factor classification methods cannot meet the developing needs of engineering, and multifactor classification methods have become increasingly common [17-21]. Many methods to evaluate the stability of underground engineering emerge in endlessly [22-26]. However, classifications and evaluations of the stability of rock surrounding underground oil storage caverns have become more prevalent in recent years. Numerical simulation and nonlinear methods are widely used in combination with the conventional classification standards for underground rock masses [27-30]. Moreover, nonlinear methods have been widely used to classify the rock masses surrounding underground oil storage caverns [31-33]. Notably, it is necessary to predict the hydrogeological grade of the rock surrounding an underground water-sealed oil storage cavern.

This research is based on an actual project. A principal component analysis ( $P C A)$-extenics model that considers the seepage quantity, groundwater hydrogen ion concentration $(p H)$, groundwater level and hardness of groundwater $(\mathrm{HoG})$ to reflect the actual hydrology grade of oil storage caverns is proposed. Then, the authors introduce the rough sets theory and use the uniaxial compressive strength $\left(\mathrm{R}_{\mathrm{c}}\right)$, rock quality designation $(R Q D)$, rock discontinuity structural plane status, angle between the hole axis and structural plane and hydrology grade as evaluation factors to calculate the weight of each factor. Finally, the authors establish a rough set-extenics model of the surrounding rock based on the weights, and the reliability of the model is assessed. The study provides references for the prediction of the hydrogeological grade and the classification of the rock masses surrounding oil storage caverns.

\section{Methodology}

\section{Principal Component Analysis}

PCA is a statistical analysis method used to classify multiple variables into a few comprehensive indexes. The method is often applied to complex systems with multiple elements, and large numbers of variables undoubtedly increase the difficulty and complexity of analyses.

Assume that there are $n$ samples, each of which has $p$ variables, forming a data matrix of $n \times p$.

$$
X=\left[\begin{array}{cccc}
x_{11} & x_{12} & \ldots & x_{1 p} \\
x_{21} & x_{22} & \ldots & x_{2 p} \\
\vdots & \vdots & \vdots & \vdots \\
x_{n 1} & x_{n 2} & \ldots & x_{n p}
\end{array}\right]
$$

Set the new variables as $z_{1}, z_{2}, z_{3}, \ldots$, and $z_{m}(m \leqq p)$ (integrated index after dimensionality reduction). Then, the following expressions can be obtained.

$$
\left\{\begin{array}{c}
z_{1}=l_{11} x_{1}+l_{12} x_{2}+\ldots+l_{1 p} x_{p} \\
z_{2}=l_{21} x_{1}+l_{22} x_{2}+\ldots+l_{2 p} x_{p} \\
\ldots \ldots \\
z_{m}=l_{m 1} x_{1}+l_{m 2} x_{2}+\ldots+l_{m p} x_{p}
\end{array}\right.
$$

Based on mathematical theory, the resulting components are the eigenvectors corresponding to the larger eigenvalues of the correlation matrix $m$. The steps in calculating the weights of PCA are as follows.

\section{Sample Matrix Standardisation}

The following standardised transformations are performed on the sample matrix elements.

$$
X_{i j}^{\prime}=\frac{x_{i j}-\bar{x}_{j}}{s_{j}}, \quad i=1,2, \ldots, n ; j=1,2, \ldots, p
$$

For which

$$
\bar{x}_{j}=\frac{\sum_{i=1}^{n} x_{i j}}{n}, \quad s_{j}^{2}=\frac{\sum_{i=1}^{n}\left(x_{i j}-\bar{x}_{j}\right)}{n-1}
$$

The normalised matrix $X^{\prime}$ can be obtained with these expressions.

\section{Calculate the Correlation Coefficient Matrix}

$$
R=\left[\begin{array}{lllc}
r_{11} & r_{12} & \cdots & r_{1 p} \\
r_{21} & r_{22} & \cdots & r_{2 p} \\
\vdots & \vdots & \vdots & \vdots \\
r_{n 1} & r_{n 2} & \cdots & r_{n p}
\end{array}\right]
$$

...where: $r_{i j}(i, j=1,2, \ldots, p)$ is the correlation coefficient of the original variables $x_{i}$ and $x_{j}$, and $r_{i j}=r_{j i}$. The corresponding computational formula is as follows.

$$
r_{i j}=\frac{\sum_{k=1}^{n}\left(x_{k i}-\bar{x}_{i}\right)\left(x_{k j}-\bar{x}_{j}\right)}{\sqrt{\sum_{k=1}^{n}\left(x_{k i}-\bar{x}_{i}\right)^{2}\left(x_{k j}-\bar{x}_{j}\right)^{2}}}
$$

We use a normalised matrix $X^{\prime}$ to determine $r_{i j}$ in the actual calculation.

\section{Calculate the Eigenvalues and Eigenvectors}

We solve the characteristic equation $|\lambda I-R|=0$, determine the eigenvalues. The unit eigenvectors $e_{i}$ $(i=1,2, \ldots, p)$ corresponding to the eigenvalues are obtained as $\sum_{j=1}^{p} e_{i j}^{2}=1$, where $e_{i j}$ represents the $j$ th component of vector $e_{i}$. 


\section{Calculate the Principal Component Contribution Rates and Principal Component Loads}

The number of principal components is determined by the variance contribution rate $\mathrm{g}(i)$.

$$
\begin{array}{r}
g(i)=\lambda_{i} / \sum_{k=1}^{p} \lambda_{k},(i=1,2, \ldots, p) \\
G(i)=\sum_{k=1}^{i} g(k),(i=1,2, \ldots, p)
\end{array}
$$

When the cumulative contribution rate $\mathrm{G}(i)$ reaches $75 \%$, sufficient information is available to reflect the original variable, and the principal component load is calculated.

$$
l_{i j}=\sqrt{\lambda_{i}} e_{i j},(i=1,2, \ldots, m ; j=1,2, \ldots, p)
$$

\section{Calculate the Weight of Each Index}

Finally, the weight vector $W$ can be obtained by normalising the index weight.

$$
w_{j}=\left|\sum_{i=1}^{m} g(i) e_{i j}\right| / \sum_{j=1}^{p} \frac{\left|\sum_{i=1}^{m} g(i) e_{i j}\right|}{G(m)}
$$

\section{Rough Set Theory}

Rough set theory is a nonlinear mathematical method. It is a method of soft computing that can be applied to analyse massive information and discover implied knowledge to expose potential trends [34].

\section{Knowledge Expression System and Decision Table}

The knowledge expression system is given as $S=(U, R)$. Subset $P$ is the condition attribute set, and $Q$ is the decision attribute set. If $\mathrm{R}=\mathrm{P} \cup \mathrm{Q}$ and $\mathrm{P} \cap \mathrm{Q} \neq \varnothing$, the decision table is $C=(U, R, P, Q)$.

\section{Support of Condition Attributes to Decision Attributes}

$$
k=\gamma_{P}(Q)=\left|\operatorname{pos}_{p}(Q)\right| /|U|
$$

Decision attribute $Q$ depends on condition attribute $P$ at the $k(0 \leqq k \leqq 1)$ level, and $\operatorname{pos}_{p}(Q)$ is the $P$ positive region of $Q$. Additionally, $\gamma_{p}(Q)$ is the dependence degree of $Q$ on $P$.

\section{Significance of Condition Attributes on Decision Making}

The support degree for the decision attribute set $Q$ follows.

$$
\gamma_{p-p_{i}}(Q)=\left|\operatorname{pos}_{p-\left\{p_{i}\right\}}(Q)\right| /|U|
$$

Additionally, the significance of subset $P_{i} \in P$ for $Q$ is as follows.

$$
\sigma_{P Q}\left(P_{i}\right)=\gamma_{P}(Q)-\gamma_{P-P_{i}}(Q)
$$
$P_{i}$

The larger $\sigma_{P Q}\left(P_{i}\right)$ is, the larger the significance of

\section{Discretisation of the Continuous Attributes}

The discretisation of constant attributes is an essential step in data processing.

Determine the maximum $x_{\max }$ and the minimum $x_{\text {min }}$ values of each attribute. Divide it into $n$ sections. Calculate the length $d=\left(x_{\max }-x_{\max }\right) / n$ of each section. Calculate $c_{1}=c_{0}+d, c_{2}=c_{1}+d, \ldots, c_{n}=x_{\max }$. When $c_{k} \leqq x \leqq c_{k+1}, p=k, k=1,2, \ldots, n$. Specifically, when $x=c_{n}, p=n-1$.

\section{Extension Theory}

Extension theory is a relatively new theory that was proposed in China. The theory can transform multiple evaluation indexes to obtain a compatibility problem and perform evaluations by establishing a matterelement model.

\section{Matter-Element}

The object is $N$, the value of the corresponding characteristic $c$ is $v$. The matter-element $R=(N, c, v)$ is used to describe an object. The object $N$ with $n$ characteristics can be expressed as follows:

$$
R=\left[\begin{array}{ccc}
N & c_{1} & v_{1} \\
& c_{2} & v_{2} \\
& \vdots & \vdots \\
& c_{n} & v_{n}
\end{array}\right]=\left\{\begin{array}{c}
R_{1} \\
R_{2} \\
\vdots \\
R_{n}
\end{array}\right\}
$$

...where $R$ is the n-dimensions matter-element, expressed as $R=(N, c, v)$.

\section{Classical Field}

$$
R_{0 t}=\left(N_{0 t}, c, v_{0 t}\right)=\left[\begin{array}{ccc}
N_{0 t} & c_{1} & <a_{0 t 1}, b_{0 t 1}> \\
& c_{2}<a_{0 t 2}, b_{0 t 2}> \\
\vdots & \vdots \\
c_{n} & <a_{0 t n}, b_{0 t n}>
\end{array}\right]
$$

...where $N_{0 t}$ represents a standard object which quality grade is $t ; c_{j}$ is a factor that influences $N_{o t}(j=1,2, \ldots$, $n) .<a_{0 t j}, b_{0 t j}>$ is the classical field. 


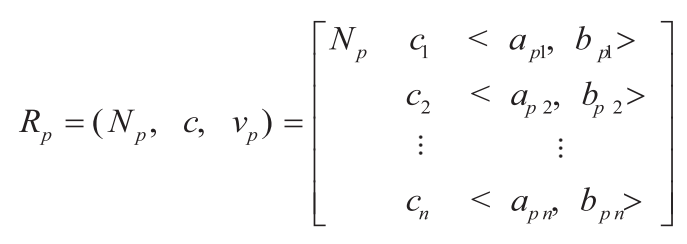

...where $c_{j}$ represents the $j$ th factor of object $N_{p}$ and $<a_{p j}$ $b_{p j}>$ is the controlled field.

\section{Matter-Element to be Evaluated}

The collected indicator information associated with the object to be evaluated $i$ must be represented by a matter element, which is denoted as $R_{i}$ :

$$
R_{i}=\left(N_{i}, c, v_{i}\right)=\left[\begin{array}{ccc}
N_{i} & c_{1} & v_{i 1} \\
& c_{2} & v_{i 2} \\
& \vdots & \vdots \\
& c_{n} & v_{i n}
\end{array}\right]
$$

...where $N_{i}$ is the $i$ th matter element to be evaluated, $c_{j}$ is a factor related to the quality of the matter-element to be evaluated $(j=1,2,3, \ldots, n), v_{i j}$ is the value of the $j$ th factor $c_{j}$ of the $i$ th object $N_{i}$, which represents the collected data.

\section{Single-Factor Correlation Degree}

The equations can calculate the correlation degree of the $j$ th factor of the $i$ th matter element to be evaluated for quality grade $t$ :

$$
k_{t i j}= \begin{cases}\frac{-\rho\left(v_{i j}, v_{0 t j}\right)}{\left|v_{0 t j}\right|} & v_{i j} \in v_{0 t j} \\ \frac{\rho\left(v_{i j}, v_{0 t j}\right)}{\rho\left(v_{i j}, v_{p j}\right)-\rho\left(v_{i j}, v_{0 t j}\right)} & v_{i j} \notin v_{0 t j}\end{cases}
$$

Where

$$
\begin{array}{r}
\rho\left(v_{i j}, v_{0 t j}\right)=\left|v_{i j}-\frac{1}{2}\left(a_{0 t j}+b_{0 t j}\right)\right|-\frac{1}{2}\left(b_{0 t j}-a_{0 t j}\right) \\
\rho\left(v_{i j}, v_{p j}\right)=\left|v_{i j}-\frac{1}{2}\left(a_{0 t j}+b_{p j}\right)\right|-\frac{1}{2}\left(b_{p j}-a_{p j}\right) \\
(i=1,2, \ldots, m ; j=1,2, \ldots, n ; t=1,2, \ldots, s) . \\
\text { Comprehensive Correlation Degree }
\end{array}
$$

The comprehensive correlation degree refers to the attribution degree of the object to be evaluated for each evaluation grade and can be expressed as follows:

$$
\begin{aligned}
& k_{t i}\left(N_{i}\right)=\sum W_{j} k_{t i j}\left(v_{i j}\right) \\
& (i=1,2, \ldots, m ; j=1,2, \ldots, n ; t=1,2, \ldots s)
\end{aligned}
$$

...where $W$ is the weight coefficient of the $j$ th factor and satisfies $\sum_{j=1}^{h} W_{j}=1$.

$$
\text { If } k_{i t_{0}}\left(N_{i}\right)=\max \left\{\mathrm{k}_{\mathrm{it}}\left(\mathrm{N}_{\mathrm{i}}\right)_{\mathrm{t}=1,2, \ldots, S}\right\} \text {, the grade of } \mathrm{N}_{\mathrm{i}} \text { is } \mathrm{t}_{0} \text {. }
$$

\section{PCA-Extenics Surrounding Rock Classification Model of an Oil Storage Cavern}

The evaluation model proposed in this paper can be divided into two parts:

A) Based on the data collected from excavated cavern sections, a hydrogeological grade evaluation system is established to evaluate the hydrogeological grade of the cavern sections.

B) The hydrogeological grade of excavated sections is considered in the surrounding rock classification.

The principles of the evaluation model are as follows.

The authors use $P C A$ to calculate the weight of each factor (seepage quantity, $p H$, groundwater level and hardness of groundwater) in the hydrogeological grade evaluation. The authors use the formulas in chapter 2 to calculate the normalised weight coefficient of each evaluation factor. Then, we use formulas (13) and (14), based on the weights and classical domain, to calculate the single-factor correlation $k_{t i j}$ and comprehensive correlation $k_{t i}\left(N_{i}\right)$ values, of which $k_{i t_{0}}\left(N_{i}\right)=\max \left\{k_{i t}\left(N_{i}\right)_{t=1,2, s, s}\right\} ;$ therefore, the hydrogeological grade of a cavern section is $t_{0}$.

The surrounding rock classification level is expressed as a decision type set $Q$, and the hydrogeological grade and the other evaluation factors are treated as conditional attribute set $P$ in decision table $C$. Then, the support degree $k$, the condition attribute, is calculated based on the formula (11), and the importance of each attribute $\sigma_{P Q}\left(P_{i}\right)$ is determined based on formulas (12) and (13). Finally, the weights of the influential factors are determined by $W_{i}=\sigma_{P Q}\left(P_{i}\right) / \sum_{i=1}^{n} \sigma_{P Q}\left(P_{i}\right)$.

The influential factors determined by experience are used as evaluation indexes for surrounding rock classification, and the weights from the previous step and the classical domain (16) values are used as evaluation parameters to calculate the single-factor correlation $k_{t i j}$ and comprehensive correlation $k_{i t}\left(N_{i}\right)$, of which $k_{i t 0}\left(N_{i}\right)=\max \left\{k_{i t}\left(N_{i}\right)_{t=1,2 \ldots, s}\right\}$. That is, the surrounding rock classification level is $t_{0}$.

\section{Research on the Hydrogeological Classification of the Rock Surrounding Underground Oil Storage Carven}

\section{Study Area}

The study area includes the first large-scale underground oil storage project in Qingdao, China. The geology condition plays an important role in the construction of the cavern, and the geological, hydrogeological and engineering geological properties of typical rock units in the area were investigated. 


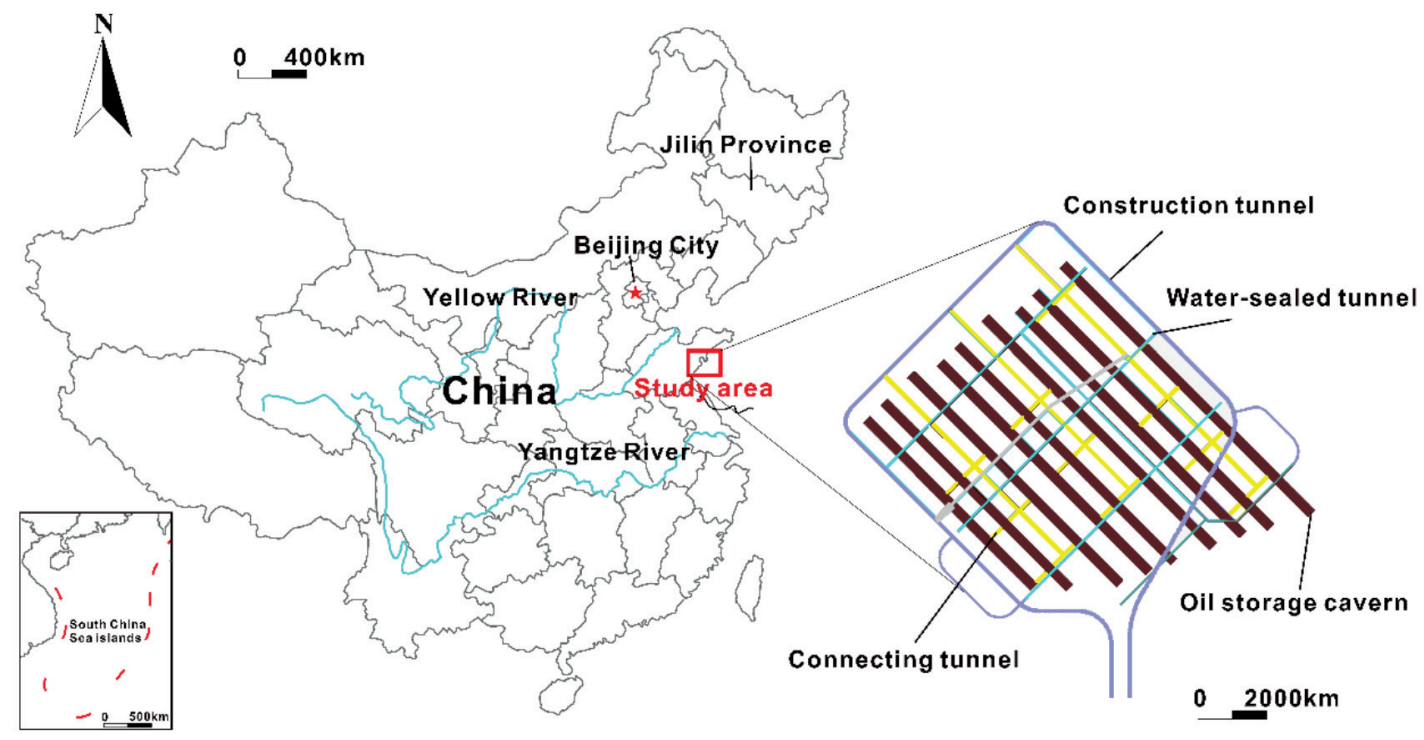

Fig. 1. The underground oil storage located at a low hilly area bordering the Yellow Sea: Layout plan of underground water-sealed oil storage cavern is oriented in the north-west direction with $600 \mathrm{~m}$ and $838 \mathrm{~m}$ width.

The construction area is a low hilly area bordering the Yellow Sea. The average ground elevation is $220 \mathrm{~m}$, and the biggest relative height difference is $253.4 \mathrm{~m}$. The underground oil storage is composed of nine caverns and is oriented in the north-west direction with $600 \mathrm{~m}$ and $838 \mathrm{~m}$ width. The underground reservoir is composed of nine caverns. The storage cavern spans $20 \mathrm{~m}$, the cavern height is $30 \mathrm{~m}$, and the cross-sectional shape is a straight wall with a round arch. The span between the cavern wall and the wall of the adjacent construction tunnel is $25 \mathrm{~m}$, and the interval between the two caverns is $30 \mathrm{~m}$ (Fig. 1) [35].

\section{Hydrogeological Factors Considered in the Surrounding Rock Evaluation}

The evaluation indexes used in surrounding rock classification must be selected based on the geological environment of the actual project. Combined with the requirements of water-sealed oil storage and the field investigation results, the following factors are selected as the influential factors based on the principles of simplicity and ease of measurement.

This research introduces a model of five evaluation factors to calculate the weight of each factor. As we can obtain from the figures (Fig. 2, Fig. 3), four rock parameters, the uniaxial compressive strength $\left(\mathrm{R}_{\mathrm{c}}\right)$, rock quality designation (RQD), rock discontinuity structural plane status (SPS), and the angle between the hole axis and structural plane $(\theta)$, have a closely relationship with the surrounding rock classification grade. Each of them has a rising or falling trend with the change of the level.

Groundwater is an important factor that affects the stability of rock masses. Water can dissolve the soluble cement in the rock and structural surface, which makes the rock soft and loose. Additionally, water can transform the infill into the mud, reduce the rock strength, increase the dynamic and hydrostatic pressures, etc. [36, 37]

The groundwater status is an important indicator that can be used to control groundwater flow fields and ensure that artificial water curtain systems function and prevent rapid decreases in groundwater levels. This research selects the following four indexes as influential factors to evaluate hydrogeological grades based on the differences between underground oil storage caverns and common tunnels. According to the figures (Fig. 4, Fig. 5), each of them has a rising or falling trend with the change of the level. This research divides the hydrogeological grades into four grades (I, II, III and IV) to meet the requirements of actual engineering.

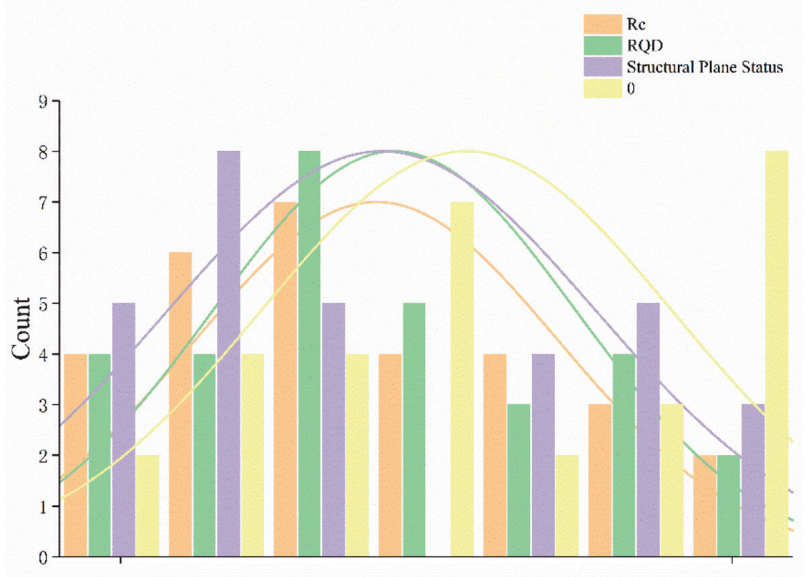

Fig. 2. Frequency distribution of rock parameters are near normal distribution. 

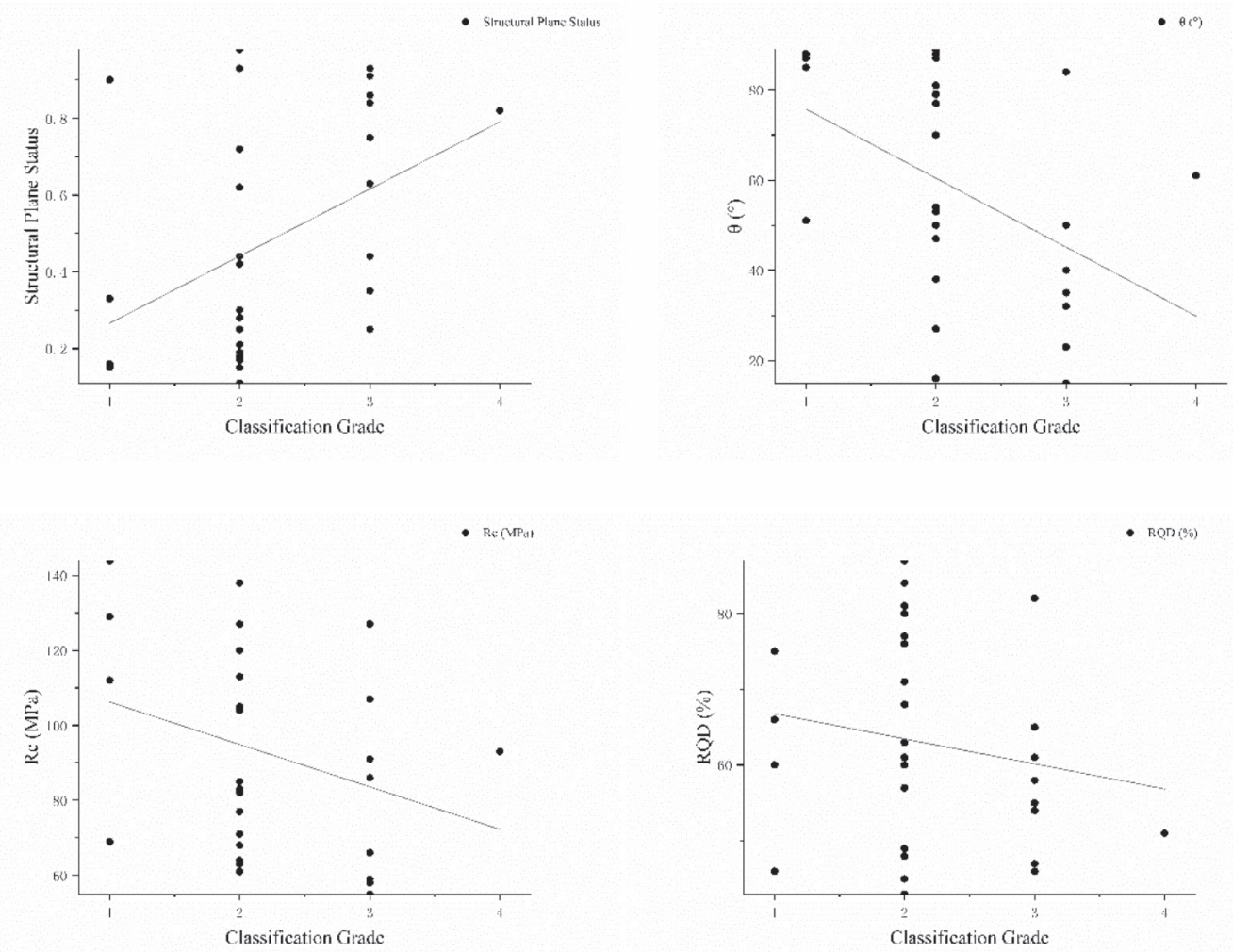

Fig. 3. The tendency of four rock parameters with change of grade.

\section{Results and Discussion}

Large underground water-sealed oil storage caverns are usually located in coastal areas with stable lithology. In this study, the authors use a nonlinear method to analyse the stability of oil storage caverns. The groundwater seepage quantity, groundwater $\mathrm{pH}$, groundwater depth and total hardness of groundwater are used to evaluate the hydrogeological conditions of oil storage for the first time. The hydrogeological grade of the underground water-sealed oil storage cavern is divided into four different levels (I, II, III and IV) based on the above analysis. The above eight evaluation indexes are quantified and discretised accordingly. The authors divide the surrounding rock mass based on four grades (Table 1), the 《Standard for the engineering classification of rock masses》(GB/T50218-2014) and related research.

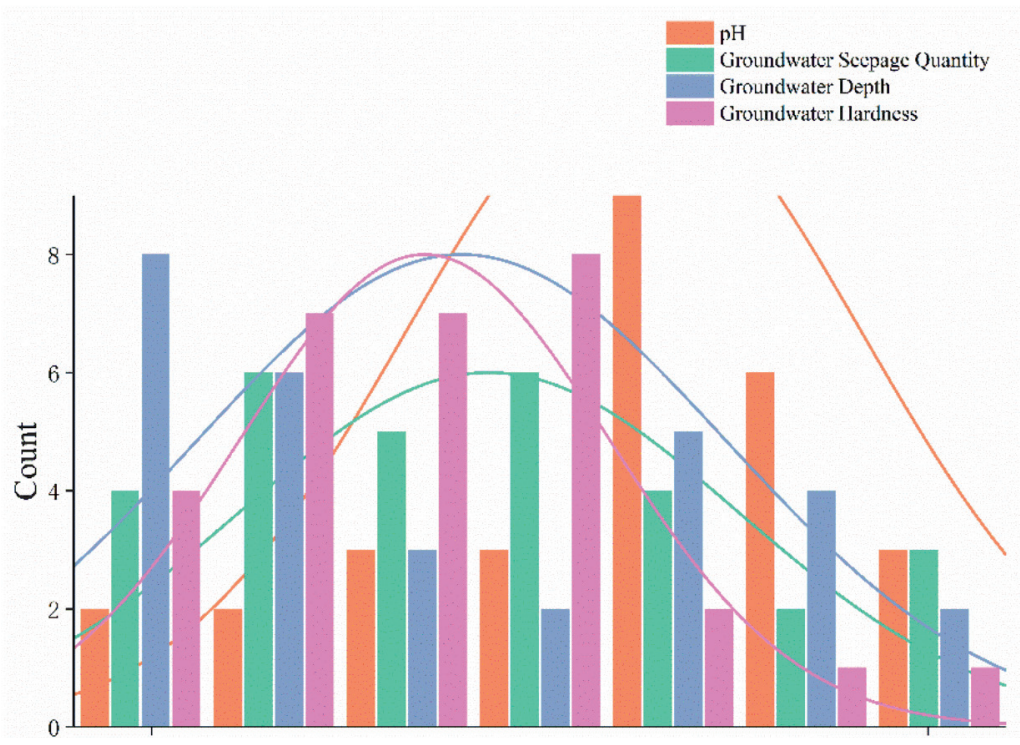

Fig. 4. Frequency distribution of groundwater parameters are also near normal distribution. 

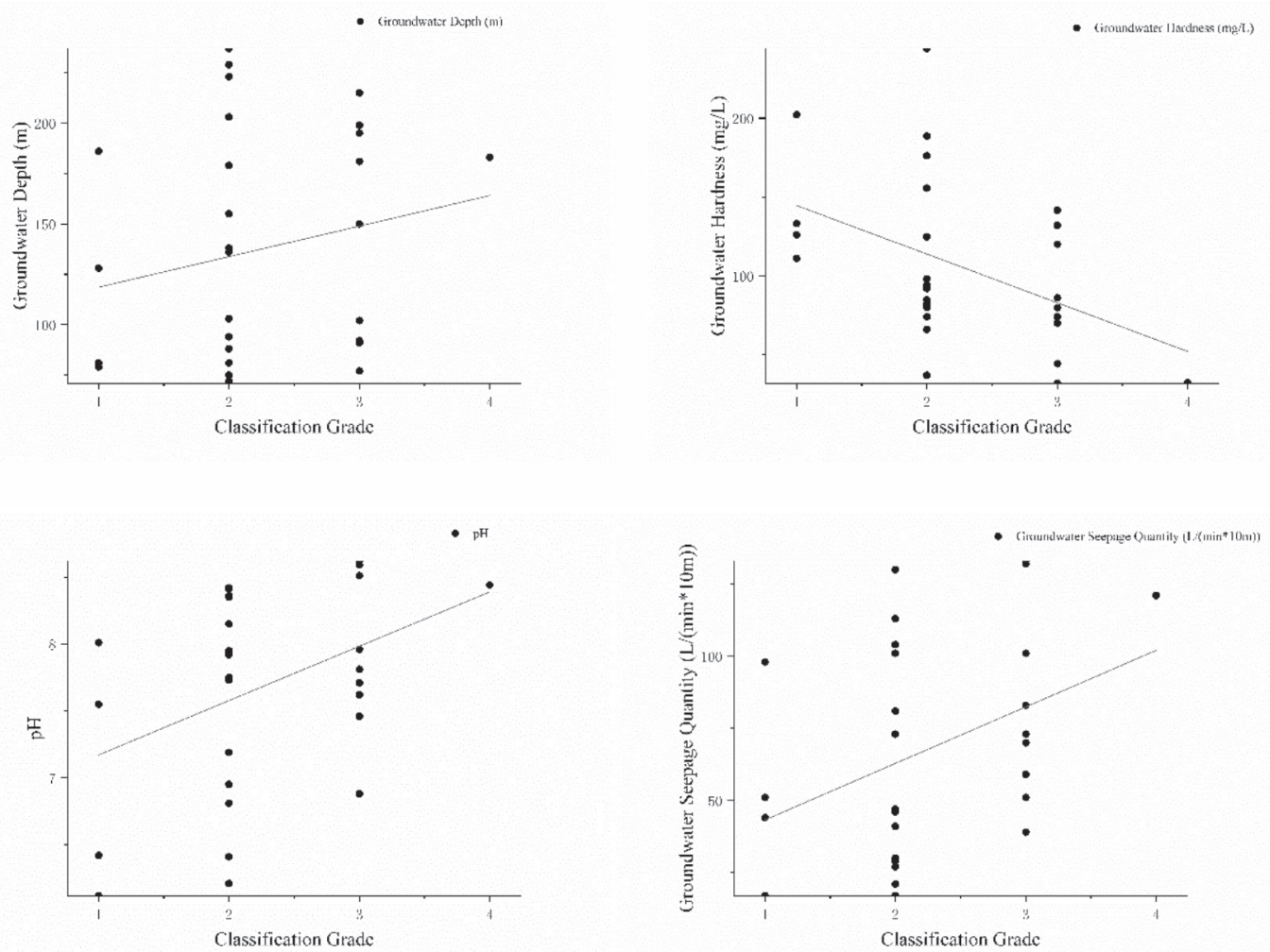

Fig. 5. The tendency of four groundwater parameters with change of grade.

The groundwater seepage quantity, groundwater depth were collected from the daily report of construction at the selected sections. The rock discontinuity structural plane status, and the angle between the hole axis and structural plane were collected from the field test when sampling. The groundwater $p H$ and $H o G$, the $R_{c}$ and $R Q D$ of rock were measured from the samples by lab testing. (Part of data in Table 2).

To ensure the normal operation of the artificial water curtain system in the oil storage cavern in the future, 30 samples are selected from the construction of the No.1 oil storage cavern, and the hydrogeological classification model established in this paper is applied. The model is used to evaluate and grade five areas of the No.1 cavern (Table 3).

Hydrogeological Grade Evaluation and Surrounding Rock Classification Results

$P C A$ is conducted to calculate the weight of each factor (seepage quantity, $p H$, groundwater level and hardness of groundwater) in the hydrogeological grade evaluation. The formulas in chapter 2 are used to calculate the normalised weight coefficient of each evaluation factor. According to formulas (3) to (10),

Table 1. Evaluation indexes and grade ranges for the rock surrounding an underground water-sealed oil storage cavern.

\begin{tabular}{|c|c|c|c|c|}
\hline & I & II & III & IV \\
\hline $\mathrm{R}_{\mathrm{c}}(\mathrm{MPa})$ & $100 \sim 150$ & $60 \sim 100$ & $30 \sim 60$ & $0 \sim 30$ \\
\hline $\mathrm{RQD}(\%)$ & $75 \sim 100$ & $50 \sim 75$ & $25 \sim 50$ & $0 \sim 25$ \\
\hline Structural plane state & $0.0 \sim 0.25$ & $0.25 \sim 0.5$ & $0.5 \sim 0.75$ & $0.75 \sim 1.0$ \\
\hline$\theta\left({ }^{\circ}\right)$ & $75 \sim 90$ & $45 \sim 75$ & $15 \sim 45$ & $0 \sim 15$ \\
\hline Hydrogeological grade & $\mathrm{I}$ & $\mathrm{II}$ & $\mathrm{III}$ & IV \\
\hline $\mathrm{GW} / \mathrm{L}^{-1}$ & $0 \sim 37.5$ & $37.5 \sim 75$ & $6.75 \sim 7.5$ & $6 \sim 6.75$ \\
\hline $\mathrm{pH}$ & $8.25 \sim 9$ & $7.5 \sim 8.25$ & $112.5 \sim 150$ \\
\hline $\mathrm{H}(\mathrm{m})$ & $195 \sim 240$ & $150 \sim 195$ & $125 \sim 200$ & $60 \sim 105$ \\
\hline $\mathrm{HoG}(\mathrm{mg} / \mathrm{L})$ & $0 \sim 50$ & $50 \sim 125$ & & $200 \sim 250$ \\
\hline
\end{tabular}


Table 2. Part of data from samples.

\begin{tabular}{|c|c|c|c|c|c|c|c|c|}
\hline & $\mathrm{R}_{\mathrm{c}} / \mathrm{MPa}$ & $\mathrm{RQD} / \%$ & $\mathrm{SPS}$ & $\theta /{ }^{\circ}$ & $\mathrm{PH}$ & $\begin{array}{c}\mathrm{GW} / \\
\mathrm{L}(\mathrm{min} / 10 \mathrm{~m})-1\end{array}$ & $\mathrm{H} / \mathrm{m}$ & $\mathrm{HoG}$ \\
\hline 1 & 64 & 77 & 0.72 & 87 & 7.19 & 104 & 229 & 98.08 \\
\hline 2 & 138 & 87 & 0.19 & 38 & 8.36 & 73 & 179 & 94.08 \\
\hline 3 & 59 & 58 & 0.75 & 40 & 8.51 & 59 & 102 & 86.07 \\
\hline 4 & 120 & 43 & 0.15 & 50 & 8.35 & 17 & 71 & 92.07 \\
\hline 5 & 91 & 61 & 0.91 & 32 & 7.96 & 51 & 77 & 74.06 \\
\hline 6 & 68 & 71 & 0.3 & 81 & 6.21 & 29 & 94 & 92.07 \\
\hline 7 & 113 & 57 & 0.21 & 38 & 6.41 & 41 & 81 & 80.06 \\
\hline 8 & 69 & 60 & 0.9 & 88 & 6.12 & 44 & 79 & 126.11 \\
\hline 9 & 85 & 76 & 0.18 & 54 & 6.81 & 21 & 103 & 82.07 \\
\hline 10 & 127 & 47 & 0.93 & 23 & 8.62 & 132 & 181 & 32.03 \\
\hline
\end{tabular}

the PCA method is used to analyse the weight of each index, and the obtained values of factors (seepage quantity, $\mathrm{pH}$, groundwater level and hardness of groundwater) are $W=\{0.2235,0.2448,0.3658,0.1659\}$

The authors establish a hydrogeological evaluation extension model based on the weights and classical domain. The formulas from chapter 2 are used to calculate the single-factor correlation $k_{t i j}$ and comprehensive correlation $k_{t i}\left(N_{i}\right)$ of the sections to be evaluated. The hydrogeological grade of cavern section $t_{0}$ is determined according to $k_{t i 0}\left(N_{i}\right)=$ $\max \left\{k_{i t}\left(N_{i}\right)_{t=1,2, \ldots, s}\right\}$.

The five influential factors $\left(\mathrm{A}_{1} \sim \mathrm{A}_{5}\right)$ are taken as conditional attributes, and the surrounding rock level is used as the decision attribute. The rough set is used to calculate the weight of each influential factor. A decision table is constructed according to the field investigation and the engineering samples. Then, the support degree of the condition attribute for a decision is calculated based on the formula (11), and the importance of attributes is determined based on formulas (12) and (13). Finally, the weights of the influential factors are equal to $\{0.2105,0.3158,0.2632$, $0.1052,0.1053\}$.

Based on the knowledge of extenics, a classification model of the rock surrounding the underground oil storage cavern is established based on the determination

Table 3. Measured values of samples from the evaluated sections.

\begin{tabular}{|c|c|c|c|c|}
\hline Position & $\mathrm{A}_{1}$ & $\mathrm{~A}_{2}$ & $\mathrm{~A}_{3}$ & $\mathrm{~A}_{4}$ \\
\hline No. 1 cavern $0+356 \sim 0+381$ & 83 & 36 & 0.48 & 68 \\
\hline No. 1 cavern $0+285 \sim 0+310$ & 89 & 72 & 0.65 & 35 \\
\hline No. 1 cavern $0+233 \sim 0+258$ & 80 & 76 & 0.32 & 47 \\
\hline No. 1 cavern $0+310 \sim 0+335$ & 93 & 57 & 0.49 & 68 \\
\hline No. 1 cavern $0+140 \sim 0+160$ & 102 & 66 & 0.36 & 67 \\
\hline
\end{tabular}

criteria (Table 1) and the weights. The prediction and validation results of the model are compared with the actual values measured after excavation, as shown in Table 4.

\section{Discussion}

A) As illustrated by the comparison of the results, the predicted grade for section No. 3 is different from and worse than the actual grade, and the prediction results of the other sections are consistent with the actual results. The reason is that the groundwater level rises due to precipitation during excavation, and this rise affects the hydrogeological grade evaluation.

B) The weights of the factors that influence rock classification for underground oil storage are $\{0.2105$, $0.3158,0.2632,0.1052,0.1053\}$. Notably, the $R Q D$ reaches 0.3158 , which is the highest value among the five factors. Combined with engineering practice, the rock integrity index has a notable impact on the seepage of groundwater and the operation of the water curtain system.

C) This research adopts two methods to determine weights: $P C A$ and rough set theory. $P C A$ is a data evaluation method based on raw data. By determining the correlation among the original variables, $P C A$ can be effectively used to determine weights when the hydrology grade of the cavern is unknown. Meanwhile, rough set theory is an objective evaluation method that has advantages in dealing with incomplete and inaccurate information. Therefore, we analyse the hydrogeological data from the messy engineering samples by rough set. The two methods used in this paper are based on existing data; which mesns, the larger the sample capacity is, the more accurate the determination of the model weights. Moreover, because the prediction model is based on samples from a specific project, the actual application will vary for different projects depending on the specific situation. 
Table 4. Validation results for the underground oil storage cavern.

\begin{tabular}{|c|c|c|c|c|c|c|}
\hline \multirow{2}{*}{ Position (No.1 Carven) } & \multicolumn{4}{|c|}{ Membership of each level } & \multirow{2}{*}{ Predicted level } & \multirow{2}{*}{ Actual level } \\
\cline { 2 - 6 } & I & II & III & IV & III & III \\
\hline $0+356 \sim 0+381$ & 0 & 0.6674 & 1 & 0.0279 & II & II $_{a}$ \\
\hline $0+285 \sim 0+310$ & 0.2533 & 1 & 0.7613 & 0 & II & I $_{b}$ \\
\hline $0+233 \sim 0+258$ & 0.7917 & 1 & 0.3476 & 0 & II & II \\
\hline $0+310 \sim 0+335$ & 0.2396 & 1 & 0.5447 & 0 & II & II \\
\hline $0+140 \sim 0+160$ & 0.5721 & 1 & 0.25 & 0 & & II \\
\hline
\end{tabular}

D) The traditional classification and evaluation methods of the rock surrounding underground facilities are mainly based on the parameters of the surrounding rock, and hydrology conditions are rarely considered. Generally, the groundwater seepage quantity is the only one used as hydrology parameter in former classification. We focuses on the influence of various hydrogeological factors on the surrounding rock. Because the external environment, especially precipitation, has a certain impact on the evaluation of hydrology grades, the hydrogeological grade predicted by the model will deviate from the actual hydrogeological grade but typically within an acceptable range.

\section{Conclusion}

1. The stability of the rock surrounding an underground water-sealed oil storage cavern is affected by many factors. Based on this investigation of an existing underground oil storage project in China, from the objective and subjective perspectives, this paper proposes five influential factors to evaluate the hydrogeological grade of the surrounding rock and determine the relevant quantitative standards. For the first time, the special hydrogeological requirements of the rock surrounding an underground water-sealed oil storage cavern are considered, and the hydrology grade of the surrounding rock is evaluated.

2. The hydrogeological grade of the excavated cavern is evaluated based on a PCA-extenics model. The factors that influence the hydrogeological grade are assessed according to rough set theory, and the weights are determined based on the evaluation results. Evidence suggests that the $R Q D$ weight reaches 0.3158 , which is the largest weight among the five influential factors. Combined with engineering practice, the rock integrity index has a considerable impact on the seepage of groundwater and the operation of the water curtain system.

3. The authors use rough set and extenics theories to predict the hydrogeological grade of surrounding rock of underground oil storage cavern and establish a rough set-extenics hydrogeological grade prediction model that can be applied in practical engineering. The model verifies the feasibility of the evaluation criteria and evaluation methods through engineering examples. The research results can provide references for the evaluation and prediction the hydrogeological grades of surrounding rock of underground oil storage caverns during the construction and operation periods.

\section{List of Symbols}

$p H$ - Groundwater hydrogen ion concentration

$R_{c}$ - Uniaxial compressive strength

$\theta$ - The angle between the hole axis and structural plane

$n$ - Samples

$p, z_{m}, x, e_{i}-$ Variables

$X_{n p,} R_{n p},-$ Matrix

$r_{i j}$ - The correlation coefficient of the original variables $x$

$e_{i j}-$ The $j$ th component of vector $e_{i}$

$L_{i j}$ - The principal component load

$w$ - Weight vector

$Q$ - Decision attribute set

$C$ - Decision table

$\operatorname{pos}_{p}(Q)-P$ positive region of $Q$

$\gamma_{p}(Q)$ - Dependence degree of $Q$ on $P$

\section{Abbreviations}

$P C A$ - Principal component analysis

$H o G$ - Hardness of groundwater

$R Q D$ - Rock quality designation

$S P S$ - Structural plane status

$R S$ - Rough set

\section{Acknowledgements}

This work is supported by grants from the "The National Natural Science Foundation of China" (Nos. 41877239, 51422904, 51379112, 41772298 and 40902084).

\section{Conflict of Interest}

The authors declare no conflict of interest. 


\section{References}

1. SHI L., ZHANG B., WANG L., WANG H.X., ZHANG H.J. Functional efficiency assessment of the water curtain system in an underground water-sealed oil storage cavern based on time-series monitoring data. Engineering Geology, 239, 79, 2018.

2. MANDAL A., CHAKRAVARTHY C.P., NANDA A., RATH R., USMANI A. Analysis and Design Approach for Large Storage Caverns. International Journal of Geomechanics, 13 (1), 69, 2013.

3. USMANI A., KANNAN G., NANDA A., JAIN S.K. Seepage Behavior and Grouting Effects for Large Rock Caverns. International Journal of Geomechanics, 15 (3), 2015.

4. WANG Z.C., LI S.C., LÜ X. Q., XUE Y.G. Parameter sensitivity of rock mass integrity for a pilot underground crude oil storage caverns during construction phase. Rock \& Soil Mechanics, 32, 488, 2011.

5. LI Z.Q., XUE Y.G., QIU D.H., XU Z.H., ZHANG X.L., ZHOU B.H., WANG X.T. AHP-Ideal Point Model for Large Underground Petroleum Storage Site Selection: An Engineering Application. Sustainability, 9 (12), 2017.

6. LIU J., ZHAO X.D., ZHANG S.J., XIE L.K. Analysis of support requirements for underground water-sealed oil storage cavern in China. Tunnelling and Underground Space Technology, 71, 36, 2018.

7. WANG H.X., ZHANG B., FU D., NDEUNJEMA A. Stability and airtightness of a deep anhydrite cavern group used as an underground storage space: A case study. Computers and Geotechnics, 96, 12-, 2018.

8. LI S.C., PING Y., WANG Z.C., XUE Y.G., LI S.C., WANG G. Assessments of containment and stability of underground crude oil storage caverns based on fluid-solid coupling theory for discrete medium. Chinese Journal of Rock Mechanics \& Engineering, 31 (11), 2161, 2012.

9. WANG M.W., XU X.Y., LI J., JIN J.L.,SHEN F.Q. A Novel Model of Set Pair Analysis Coupled with Extenics for Evaluation of Surrounding Rock Stability. Mathematical Problems in Engineering, 2015, 1, 2015.

10. WINN K., NG M., WONG L.N.Y. Stability Analysis of Underground Storage Cavern Excavation in Singapore. Procedia Engineering, 191, 1040, 2017.

11. ZHANG N., SHI X.L., WANG T.T., YANG C.H., LIU W., MA H.L., DAEMEN J.J.K. Stability and availability evaluation of underground strategic petroleum reserve (SPR) caverns in bedded rock salt of Jintan, China. Energy, 134, 504, 2017.

12. ZHUANG D.Y., TANG C.A., LIANG Z.Z., MA K., WANG S.Y., LIANG J.Z. Effects of excavation unloading on the energy-release patterns and stability of underground watersealed oil storage caverns. Tunnelling and Underground Space Technology, 61, 122, 2017.

13. DEERE D.U., DEERE D.W. The Rock Quality Designation (RQD) Index in Practice, Rock Classification System for Engineering Purpose. In Symposium on Rock Classification Systems for Engineering Purposes, Cincinnati, Ohio, USA, 1988.

14. DEERE D.U., MILLER R.P. Engineering Classification and Index Properties for Intact Rock. In Deformation Curve, pp. afwl-tr-65-116, 1966.

15. LAUFFER H. Classification for tunnel construction, 1958.

16. TERZAGHI K. Rock Defects and Loads on Tunnel Supports: Rock Tunneling with Steel Supports. Commercial Shearing \& Stamping Co, Ohio, 1946.
17. AYDAN Ö., ULUSAY R., TOKASHIKI N. A New Rock Mass Quality Rating System: Rock Mass Quality Rating (RMQR) and Its Application to the Estimation of Geomechanical Characteristics of Rock Masses. Rock Mechanics and Rock Engineering, 47 (4), 1255, 2013.

18. BARTON N.R., LIEN R., LUNDE J. Engineering classification of rock masses for the design of tunnel support. Rock Mechanics and Rock Engineering, 6 (4), 189, 1974.

19. BIENIAWSKI Z.T. Geomechanics classification of rock masses and its application in tunneling. In Third Congress Int. Soc. Rock Mech., 12, 141, Denver, 1974.

20. BIENIAWSKI Z.T. Exploration for rock engineering. In Symposium on Exploration for Rock Engineering, 14, 161, Johannesburg, 1976.

21. WICKHAM G.E., TIEDEMANN H.R., SKINNER E.H. Support determinations based on geologic predictions. Proc., International Journal of Rock Mechanics smining Sciences \& Geomechanics Abstracts, 12 (7), 95, 1975.

22. WANG Y.C., JING H.W., SU H.J., XIE J.Y. Effect of a Fault Fracture Zone on the Stability of Tunnel-Surrounding Rock. International Journal of Geomechanics, 17 (6), 2017.

23. WILSON D.W., ABBO A.J., SLOAN S.W., LYAMIN A.V. Undrained Stability of Dual Circular Tunnels. International Journal of Geomechanics, 14 (1), 69, 2014.

24. WU W., ZHU H.H., LIN J.S., ZHUANG X.Y., MA G.W. Tunnel stability assessment by 3D DDA-key block analysis. Tunnelling and Underground Space Technology, 71, 210, 2018

25. XING Y., KULATILAKE P.H.S.W., SANDBAK L.A. Investigation of Rock Mass Stability Around the Tunnels in an Underground Mine in USA Using ThreeDimensional Numerical Modeling. Rock Mechanics and Rock Engineering, 51 (2), 579, 2017.

26. ZHOU X.P., HUANG X.C., LI J.X. Reliability Assessment of Tunnel Based on P -Wave Seismic Velocity. International Journal of Geomechanics, 18 (11), 2018.

27. CHEN H.M., ZHAO Z.Y., CHOO L.Q., SUN J.P. Rock Cavern Stability Analysis Under Different Hydro-Geological Conditions Using the Coupled Hydro-Mechanical Model. Rock Mechanics and Rock Engineering, 49 (2), 555, 2015.

28. JORDÁ-BORDEHORE L. Stability Assessment of Natural Caves Using Empirical Approaches and Rock Mass Classifications. Rock Mechanics and Rock Engineering, 50 (8), 2143, 2017.

29. PERROTTI M., LOLLINO P., FAZIO N.L., PISANO L., VESSIA G., PARISE M., FIORE A., LUISI M. Finite Element-Based Stability Charts for Underground Cavities in Soft Calcarenites. International Journal of Geomechanics, 18 (7), 2018.

30. WANG Z.C., GLAIS Y., QIAO L.P., HUANG A., LIU J. Hydro-geochemical analysis of the interplay between the groundwater, host rock and water curtain system for an underground oil storage facility. Tunnelling and Underground Space Technology, 71, 466, 2018.

31. WANG Z.C., LI S.C., QIAO L.P. Assessment of HydroMechanical Behavior of a Granite Rock Mass for a Pilot Underground Crude Oil Storage Facility in China. Rock Mechanics and Rock Engineering, 48 (6), 2459, 2015.

32. XUE Y.G., LI S.C., QIU D.H. Classification model of surrounding rock of underground oil storage caverns based on weights back analysis method and efficacy coefficient method and its application. Rock \& Soil Mechanics, 34 (12), 3549, 3560, 2013. 
33. ZHANG X.Y. Based on extension method of Huizhou underground oil storage caverns rock quality evaluation, China university of Geosciences (Beijing), 2010.

34. XUE Y.G., ZHANG X.L., LI S.C., QIU D.H., SU M.X., LI L.P., LI Z.Q., TAO Y.F. Analysis of factors influencing tunnel deformation in loess deposits by data mining: A deformation prediction model. Engineering Geology, 232, 94, 2018.

35. XUE Y.G., LI S.C., QIU D.H., WANG Z.C., LI Z.Q., TIAN H., SU M.X., YANG W.M., LIN C.J., ZHU J.Y. A new evaluation method for site selection of large underground water-sealed petroleum storage depots. SCIENCE CHINA Technological Sciences, 58 (6), 967, 2015.

36. LIU R., YU L., JIANG Y. Quantitative Estimates of Normalized Transmissivity and the Onset of Nonlinear Fluid Flow Through Rough Rock Fractures. Rock Mechanics and Rock Engineering, 50 (4), 1063, 2016.

37. YU L., LIU R., JIANG Y. A Review of Critical Conditions for the Onset of Nonlinear Fluid Flow in Rock Fractures. Geofluids, 2017, 1, 2017. 
